\title{
Cells adapt to the epigenomic disruption caused by histone deacetylase inhibitors through a coordinated, chromatin-mediated transcriptional response
}

\author{
John A Halsall, Nil Turan, Maaike Wiersma and Bryan M Turner*
}

\begin{abstract}
Background: The genome-wide hyperacetylation of chromatin caused by histone deacetylase inhibitors (HDACi) is surprisingly well tolerated by most eukaryotic cells. The homeostatic mechanisms that underlie this tolerance are unknown. Here we identify the transcriptional and epigenomic changes that constitute the earliest response of human lymphoblastoid cells to two HDACi, valproic acid and suberoylanilide hydroxamic acid (Vorinostat), both in widespread clinical use.

Results: Dynamic changes in transcript levels over the first $2 \mathrm{~h}$ of exposure to HDACi were assayed on High Density microarrays. There was a consistent response to the two different inhibitors at several concentrations. Strikingly, components of all known lysine acetyltransferase (KAT) complexes were down-regulated, as were genes required for growth and maintenance of the lymphoid phenotype. Up-regulated gene clusters were enriched in regulators of transcription, development and phenotypic change. In untreated cells, HDACi-responsive genes, whether up- or down-regulated, were packaged in highly acetylated chromatin. This was essentially unaffected by HDACi. In contrast, $\mathrm{HDACi}$ induced a strong increase in $\mathrm{H} 3 \mathrm{~K} 27 \mathrm{me} 3$ at transcription start sites, irrespective of their transcriptional response. Inhibition of the H3K27 methylating enzymes, EZH1/2, altered the transcriptional response to HDACi, confirming the functional significance of H3K27 methylation for specific genes.

Conclusions: We propose that the observed transcriptional changes constitute an inbuilt adaptive response to HDACi that promotes cell survival by minimising protein hyperacetylation, slowing growth and re-balancing patterns of gene expression. The transcriptional response to HDACi is mediated by a precisely timed increase in $\mathrm{H} 3 \mathrm{~K} 27 \mathrm{me} 3$ at transcription start sites. In contrast, histone acetylation, at least at the three lysine residues tested, seems to play no direct role. Instead, it may provide a stable chromatin environment that allows transcriptional change to be induced by other factors, possibly acetylated non-histone proteins.
\end{abstract}

Keywords: Histone modification, Chromatin, Gene expression, Histone deacetylase inhibitors, Polycomb complex, Valproic acid, Suberoylanilide hydroxamic acid

\section{Background}

Levels of histone acetylation across the genome reflect a dynamic equilibrium between the activities of two enzyme families, lysine acetyltransferases (KATs) and

\footnotetext{
*Correspondence: b.m.turner@bham.ac.uk

Chromatin and Gene Expression Group, School of Cancer Sciences, College of Medical and Dental Sciences, University of Birmingham, Birmingham B15 2TT, UK
}

histone deacetylases (HDACs) [1, 2]. HDAC activity can be suppressed by a variety of naturally occurring and synthetic compounds, resulting in a detectable increase in global histone acetylation after $10 \mathrm{~min}$ or less, and hyperacetylation of over $90 \%$ of $\mathrm{H} 4$ molecules after just a few hours, indicating that most of the genome is acted on by KATs and HDACs $([3,4]$ and references therein). 
This conclusion is consistent with studies on the genomic distribution of these enzymes [5-9].

Like other post-translational histone modifications, acetylation rarely acts in isolation, but as part of a combination of different modifications, usually along the histone $\mathrm{N}$-terminal tails, that collectively regulate chromatin function [10-12]. They do this either by directly influencing chromatin structure, or by serving as docking sites for non-histone proteins which, in turn, exert functional change [13-15]. In view of this, generalisations about the functional roles of particular modifications are rarely appropriate or useful. However, there is a long-standing connection between relatively high levels of overall histone acetylation and transcriptional activity [16-18]. This association is supported by more recent epigenomic studies [19-24], and by experiments on the functional consequences of acetylation of specific histone lysines. For example, enhanced acetylation of $\mathrm{H} 4$ specifically at lysine 16 is a marker of the transcriptionally hyperactive male X chromosome in D. melanogaster $[25,26]$ and has recently been linked more generally to transcriptionally active genes [27]. H3K9 acetylation is consistently enhanced at gene promoter regions [28, 29], while H3K27 acetylation protects this residue from methylation by the Polycomb silencing Complex PRC2 and consequent longterm suppression of transcription [30, 31].

In view of this, it is puzzling that cells can tolerate so well the massive hyperacetylation of core histones, and other proteins, caused by histone deacetylase inhibitors (HDACi). Many cultured cell types, including nontransformed lines such as mouse embryonic stem cells, continue to grow, albeit slowly, in the presence of HDACi $[32,33]$ and whole organisms continue to function [34, 35]. Indeed, various HDACi have been in clinical use for many years. Valproic acid (VPA), a short-chain fatty acid, is an effective anti-epileptic and mood stabiliser [36], while VPA and chemically more complex HDACi such as hydroxamic acid derivatives and depsipeptide, have been tested against a variety of cancers [37-40]. It has been known for some time that cultured cells treated with HDACi do not undergo a global up-regulation of transcription. In fact, only a small proportion of genes significantly change expression, and up to half of these are down-regulated [41-45]. These findings raise fundamental questions regarding the relationship between histone acetylation and transcription, and about the mechanisms by which cells might protect their transcriptional programmes from the potentially disruptive effects of induced epigenetic change.

Attempts to define the processes through which HDACi influence cell function, are complicated by the fact that they usually inhibit several different members of the 18-strong HDAC family. The most commonly used HDACi, including short-chain fatty acids and hydroxamic acid derivatives, inhibit the class I and IIa enzymes, HDACs 1, 2, 3, 6 and 8, of which HDACs 1-3 are consistently chromatin associated and likely to be key players in regulation of gene expression [5]. These enzymes are catalytically active only when physically associated with specific partner proteins and four complexes have been isolated and characterised, namely CoRest, NuRD, Sin3 and NCoR/SMRT [46-48]. Class IIb and IV enzymes have little or no catalytic activity, while the NAD-dependent Class III enzymes (the Sirtuins, SIRT17) have a different catalytic mechanism and are unaffected by HDACi $[49,50]$. Finally, each of the class I/IIa HDACs has multiple substrates, both histones and nonhistone proteins, including various acetyltransferases and deacetylases [51-53].

Most previous work to explore cellular responses to HDACi has used treatment times of at least $4 \mathrm{~h}$ and often $24 \mathrm{~h}$ or longer, making it impossible to identify the key processes that underpin, and initiate, what is inevitably a complex and changing response. The experiments described here define the sequential transcriptional and histone modification changes that constitute the early response (within $2 \mathrm{~h}$ ) of human cells to VPA and suberoylanilide hydroxamic acid (SAHA). The results reveal a coordinated transcriptional response that promotes cell survival by minimising protein hyperacetylation, slowing growth and re-balancing patterns of gene expression. Unexpectedly, the response involves a precisely timed increase in $\mathrm{H} 3 \mathrm{~K} 27 \mathrm{me} 3$ at transcription start sites, but little or no increase in histone acetylation, whose role seems to be to provide a stable chromatin environment that allows transcription to be modified by other factors.

\section{Results}

All experiments were carried out with human lymphoblastoid cell lines, derived from B-lymphocytes immortalized, but not fully transformed, by Epstein Barr Virus (EBV, [54]). To explore the earliest transcriptional responses to $\mathrm{HDACi}$, we treated cells, in triplicate, with either sodium valproate or SAHA for $0,30,60$ and $120 \mathrm{~min}$. We tested three concentrations of each inhibitor, covering a 25 -fold range. A progressive increase in histone acetylation was detectable by western blotting at all concentrations of both inhibitors (Additional file 1A). No change in cell cycle profile or the frequency of apoptotic cells was detectable within 120 min, but after $24 \mathrm{~h}$ both inhibitors slowed cell cycle progression and, at the highest concentrations tested, induced a small proportion (8-10\%) of apoptotic cells (Additional file 1B).

To monitor changes in transcription, fluorescentlylabelled cDNA from each sample was applied to a Nimblegen HD2 135K array, on slides each containing 12 
such arrays. Thus, a time-course experiment $(0,30,60$, $120 \mathrm{~min}$ ), in triplicate, could be accommodated on a single slide. We used $t$ tests $(P<0.05$, fold change $>1.5)$ to identify genes whose transcript levels were significantly changed, relative to $t_{0}$, at each time point. After $120 \mathrm{~min}$ at the highest concentration of each inhibitor, about $7 \%$ of elements on the array showed significantly up- or down-regulated expression, in approximately equal numbers (Fig. 1).

\section{Defined gene populations show characteristic expression changes over time}

Genes were clustered into categories according to how their expression changed over time. The clustering algorithm was allowed to select the number of groups, which ranged from $4(0.5 \mu \mathrm{M}$ SAHA) to $10(2.5 \mu \mathrm{M}$ SAHA), with just 2 for $0.2 \mathrm{mM}$ VPA, where only 22 genes met the selection criteria. This strategy resulted in a few groups that contained only a small number of genes and, for clarity, only those groups containing $>1 \%$ of the total number of genes analysed are shown in the figures. At every concentration except for $0.2 \mathrm{mM} \mathrm{VPA}$, the great majority of responding genes behaved in one of four general ways, namely progressively increasing from $t_{0}$, progressively decreasing from $t_{0}$, increasing after an initial lag and decreasing after an initial lag. Results for $1 \mathrm{mM}$ VPA and $2.5 \mu \mathrm{M}$ SAHA are shown in Fig. 2 and for the remaining concentrations in Additional file 2. The two groups from $0.2 \mathrm{mM}$ VPA treatment are shown as a heat-map in Additional file $3 \mathrm{~A}$.

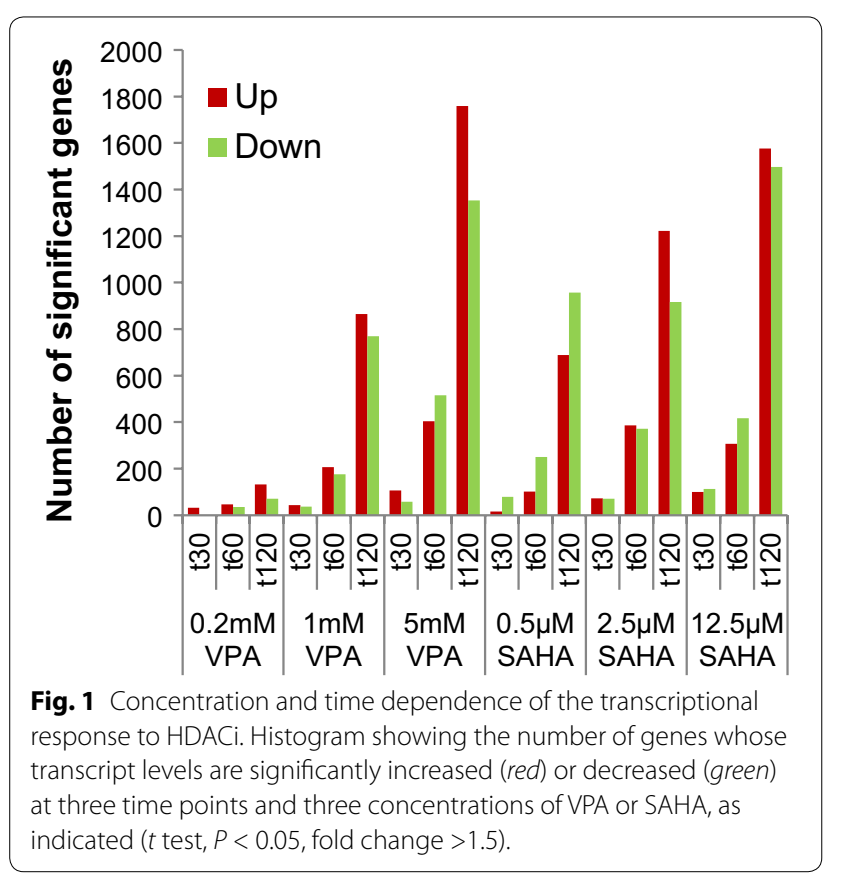

For each inhibitor, there was a strong overlap between genes responding at the different concentrations tested (Fig. 3a) and between SAHA and VPA (Fig. 3b). For example, combining genes regulated at all doses of each inhibitor, $73 \%$ of those genes responding to VPA also responded to SAHA. It is particularly interesting to see that of the 22 genes whose transcription is significantly affected by $0.2 \mathrm{mM}$ VPA (listed in Additional file 4), 21 are also affected at higher concentrations of VPA (Fig. 3a) and 19 are affected by SAHA (Fig. 3b). This gives confidence that despite the small numbers involved and the very low dose of VPA, the changes detected are part of the same cellular response triggered at higher concentrations.

\section{A coordinated transcriptional response to $\mathrm{HDACi}$}

Ontology analysis (DAVID, [55]) was used to characterise the genes within each of the four groups identified by clustering for 1 and $5 \mathrm{mM} \mathrm{VPA}$ and all concentrations of SAHA (Fig. 2, Additional file 2). Early and late responding genes, whether up- or down-regulated and at all concentrations of both inhibitors, were highly enriched in genes involved in transcriptional regulation. These included a large number of DNA-binding zinc finger proteins (Fig. 2, Additional file 2).

There was universal down-regulation of genes encoding components of lysine acetyltransferases (KAT) complexes, always following an initial delay (Fig. 2, Additional file 2). Table 1 shows the $12 \mathrm{KAT}$ complex members that were down-regulated and the extent of the observed change. Between them, the down-regulated KAT complexes acetylate all four core histones, along with an unknown number of non-histone proteins.

Genes within the "cytokine activity" term were rapidly down-regulated by both inhibitors (Fig. 2). Across all experiments, this category comprised 41 genes, most of which are involved in the differentiation or function of lymphocytes and other cells of the immune system (Additional file 5). They include 6 interleukins and 12 genes from the Interferon alpha (IFNA) cluster on chromosome 9. We note also that the TGF-beta superfamily gene GDF9, essential for G1-S and G2-M progression [56], and its paralogue GDF15, are consistently downregulated (Additional file 5); this response can explain the characteristic change in cell cycle profile induced by HDACi (Additional file 1).

Developmental terms such as "pattern specification process" and "HOX genes" were up-regulated, following a lag, by both inhibitors (Fig. 2). The "pattern specification process" category included 51 genes that were significantly up-regulated in at least one of the five experiments shown in Fig. 2 and Additional file 2. Amongst these genes (listed in Additional file 6) we find 13 homeobox 


\section{$1 \mathrm{mM}$ VPA}

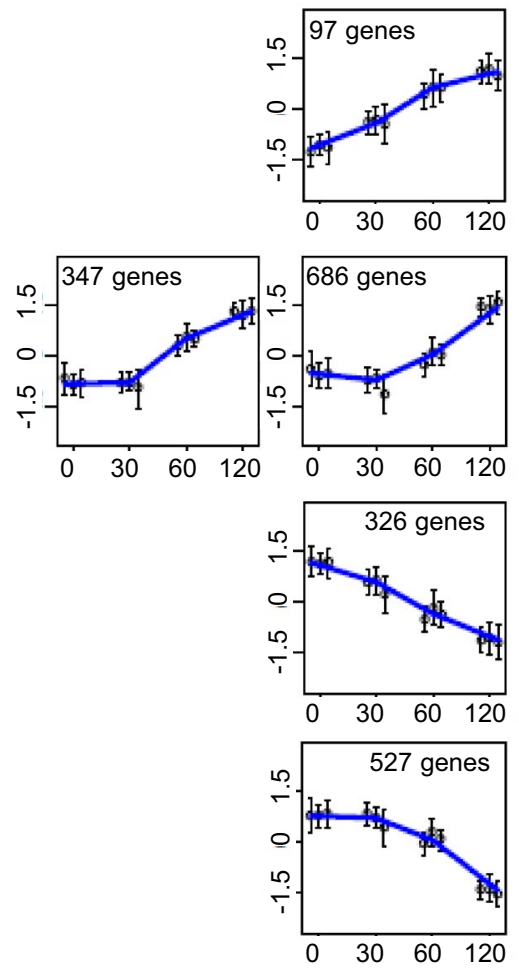

공

GOBP positive regulation of gene expression

GOBP regulation of transcription

GOBP regulation of transcription

GOMF transcription repressor activity

GOBP pattern specification process

GOBP sensory organ development

GOBP skeletal system development

GOMF cytokine activity

GOBP regulation of transcription

GOBP regulation of transcription

GOCC histone acetyltransferase complex

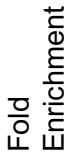

$121.5 \times 10^{-5} \quad 5.1$

$226.1 \times 10^{-4} \quad 2.1$

$1263.6 \times 10^{-8} \quad 1.6$

$305.4 \times 10^{-8} \quad 3.2$

$247.9 \times 10^{-6} \quad 2.9$

$20 \quad 8 \times 10^{-5} \quad 2.8$

$241.3 \times 10^{-4} \quad 2.5$

$151.2 \times 10^{-9} \quad 8.8$

$401.1 \times 10^{-3} \quad 1.6$

$78 \quad 6 \times 10^{-11} \quad 2.0$

$\begin{array}{lll}6 & 3 \times 10^{-4} & 10.1\end{array}$

\section{5 $\mu \mathrm{M}$ SAHA}
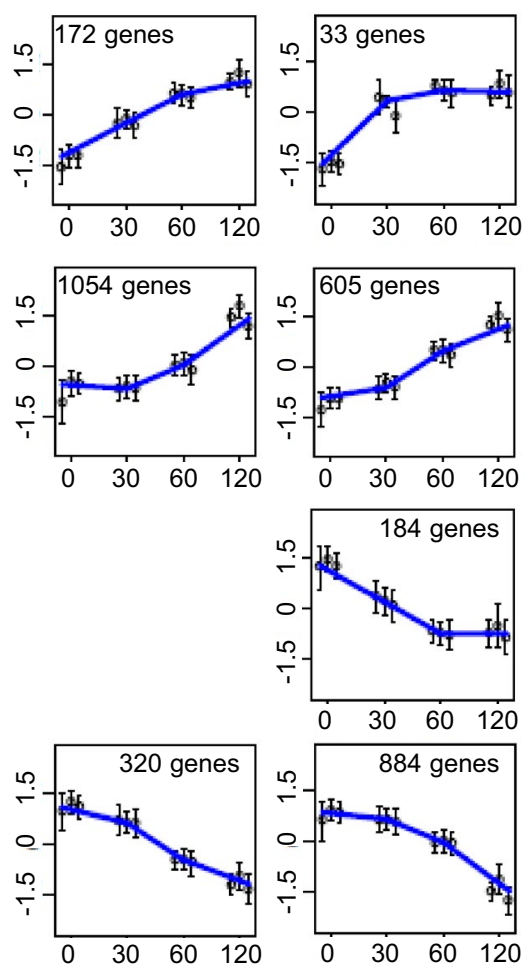

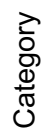

Term

P-Value

는 는

GOBP regulation of transcription

$286.6 \times 10^{-3} \quad 1.6$

GOBP pattern specification process

$319.8 \times 10^{-6} \quad 2.5$

GOMF DNA binding

$1372.4 \times 10^{-4} \quad 1.3$

GOBP regulation of transcription

$1575.8 \times 10^{-4} \quad 1.3$

GOMF transcription repressor activity

$331.1 \times 10^{-5} \quad 2.4$

GOBP protein amino acid phosphorylation

$532.5 \times 10^{-4} \quad 1.7$

GOMF ligand-dependent nuclear receptor

$109.3 \times 10^{-4} \quad 3.9$

GOBP tube development

$251.2 \times 10^{-4} \quad 2.4$

GOMF cytokine activity

$168.9 \times 10^{-13} 13.0$

GOBP regulation of transcription

$352 \times 10^{-6} \quad 2.2$

GOBP regulation of transcription

$1648.7 \times 10^{-20} \quad 2.0$

GOBP defense response

$342.8 \times 10^{-3} \quad 1.7$

GOCC histone acetyltransferase complex

$71.2 \times 10^{-3} \quad 5.8$

GOBP taxis

$175.8 \times 10^{-5} \quad 3.3$ 
(See figure on previous page.)

Fig. 2 Dynamics and ontology of the transcriptional response to HDACi. Significant genes were identified by ANOVA (fold change $>1.5$, FDR $<10 \%$ ) and clustered by SOTA. The four major clusters represent genes that were up- or down-regulated, either with or without a delay. Minor clusters, containing less than $1 \%$ of all genes, are not shown. Each subset of genes was subject to ontological analysis by DAVID. For each significant annotation cluster (enrichment score $>2$ ) the top ontological term is shown. For each gene ontology term, count refers to the number of significant genes involved in that term, fold enrichment represents the enrichment in the significant gene list, of genes involved in that term relative to background, and the $P$ value is a measure of the significance of that enrichment.

genes and multiple genes encoding components of the Wnt, Shh and Notch signalling pathways $(6,4$ and 3 respectively).

The lowest concentration of VPA tested $(0.2 \mathrm{mM})$ is within the range likely to be achieved in the body fluids of patients taking therapeutic doses of VPA [57]. By
ANOVA, we identified just 22 genes responding at this dose at $30 \mathrm{~min}$ and thereafter. Of these, 17 were up- and 5 down-regulated (Additional files 3, 4). Amongst the down-regulated minority was $\mathrm{EPC} 2$, a paralogue of the HAT component EPC1 (Table 1). Of the 17 up-regulated genes, the great majority (at least 15) encode transcription

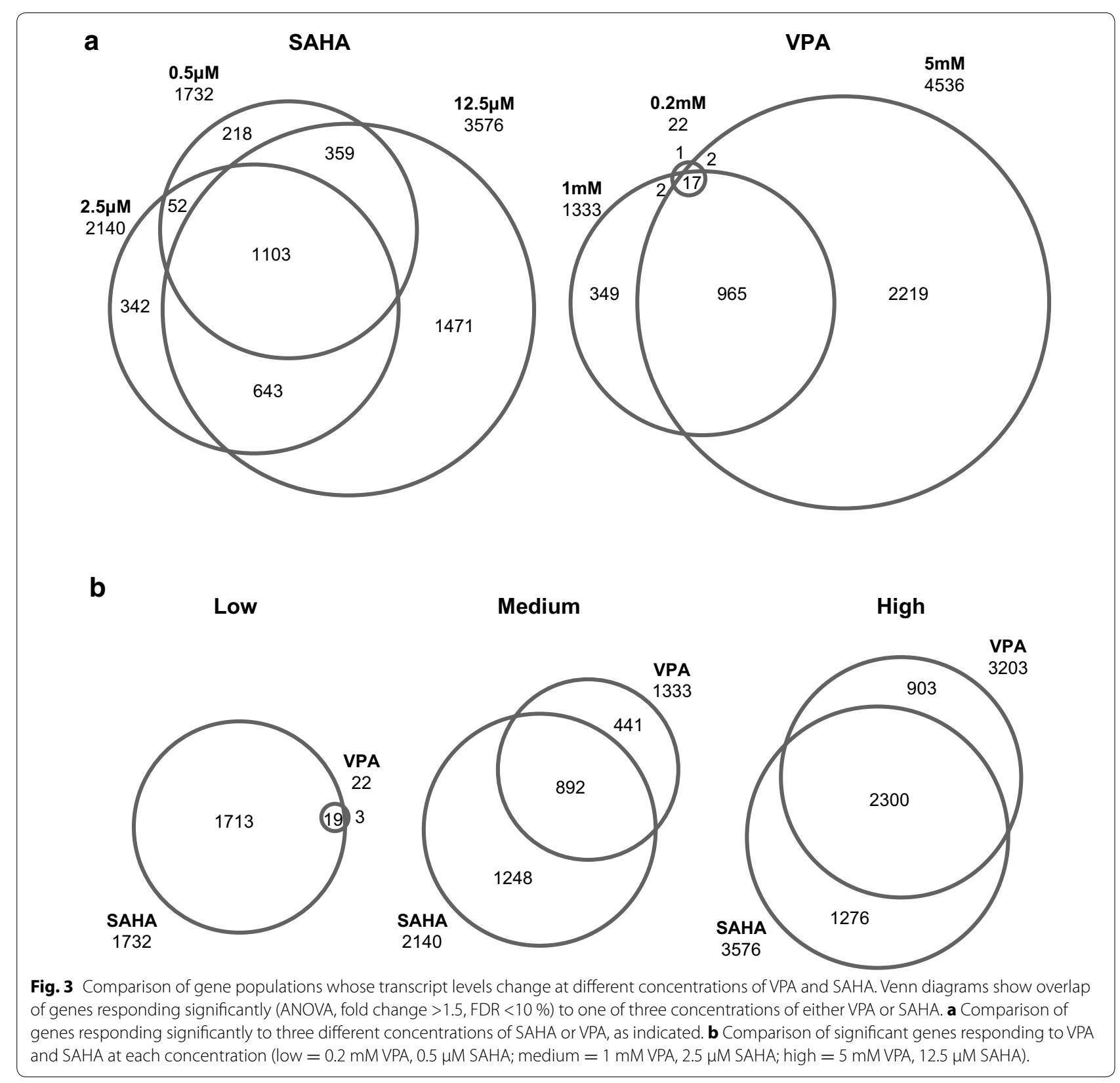


Table 1 Genes encoding components of KAT complexes are consistently down-regulated by HDACi

\begin{tabular}{|c|c|c|c|c|c|c|c|c|c|c|c|c|}
\hline Gene & MYST2 & PHF17 & PHF15 & ING5* & BRPF3 & MYST4 & ING3 & $E P C 1$ & YEATS4 & CSRP2BP & TAF6L & CREBBP \\
\hline Complex & \multicolumn{4}{|c|}{ HBO1 } & \multicolumn{2}{|c|}{ MOZ/MORF } & \multicolumn{3}{|c|}{ NuA4 } & ATAC & PCAF & p300/CBP \\
\hline Histone Target & \multicolumn{4}{|c|}{$\mathrm{H} 4$} & \multicolumn{2}{|c|}{ H3 } & \multicolumn{3}{|c|}{$\mathrm{H} 4 / \mathrm{H} 2 \mathrm{~A}$} & $\mathrm{H} 3 / \mathrm{H} 4$ & $\mathrm{H} 3 / \mathrm{H} 4$ & $\begin{array}{c}\mathrm{H} 2 \mathrm{~A}, \mathrm{H} 2 \mathrm{~B}, \\
\mathrm{H} 3, \mathrm{H} 4\end{array}$ \\
\hline $1 \mathrm{mM}$ VPA & 0.60 & 0.61 & 0.75 & 0.47 & 0.50 & 0.61 & 0.63 & 0.43 & 0.73 & 0.69 & 0.76 & 0.71 \\
\hline $5 \mathrm{mM}$ VPA & 0.52 & 0.43 & 0.63 & 0.50 & 0.48 & 0.75 & 0.55 & 0.38 & 0.75 & 0.61 & 0.66 & 0.76 \\
\hline $0.5 \mu \mathrm{M}$ SAHA & 0.60 & 0.57 & 0.61 & 0.51 & 0.43 & 0.70 & 0.84 & 0.46 & 0.74 & 0.71 & 0.63 & 0.77 \\
\hline $2.5 \mu \mathrm{M}$ SAHA & 0.48 & 0.48 & 0.49 & 0.53 & 0.44 & 0.62 & 0.90 & 0.36 & 0.70 & 0.64 & 0.75 & 0.66 \\
\hline $12.5 \mu \mathrm{M}$ SAHA & 0.45 & 0.40 & 0.49 & 0.48 & 0.38 & 0.55 & 0.63 & 0.46 & 0.62 & 0.60 & 0.72 & 0.63 \\
\hline
\end{tabular}

The table shows the fold change between 0 and 120 min of genes encoding KAT complex proteins at the inhibitor concentrations shown. Statistically significant changes (ANOVA, fold change $>1.5$, FDR $<10 \%$ ) are shaded in green. No KATs were significantly down-regulated by $0.2 \mathrm{mM} \mathrm{VPA}$.

* ING5 is reported to be a member of the $\mathrm{HBO} 1$ and MOZ/MORF complexes.

factors and proteins involved in growth control and developmental signalling. In other words, the ontology closely resembles that observed at much higher concentrations.

A novel mass spectrometric approach has been used to measure the in vivo sensitivity of individual HDAC complexes (CoREST, NCoR, NURD, Sin3) to inhibitors, and has shown that they differ widely in their sensitivities to VPA, with mean $\mathrm{Kd}$ values from 0.6 to $13 \mathrm{mM}$ [58]. In view of this, one might expect to find different gene sets responding at different VPA concentrations. Despite a careful analysis over a 25 -fold concentration range, we find no evidence that the characteristic gene composition of the transcriptional response to VPA varies with inhibitor concentration.

\section{Early and progressive changes in histone modification in response to $\mathrm{HDACi}$}

We used Chromatin ImmunoPrecipitation and highthroughput sequencing (ChIP-seq) to follow changes in histone modification after 30,60 and 120 min treatment with $1 \mathrm{mM}$ VPA. We used antisera specific for H3K9ac and H4K16ac, both associated with transcriptionally active genes [27, 28], and the Polycomb-associated silencing mark H3K27me3 and its activating counterpart H3K27ac [30]. Histone modification levels were analysed using probes from $500 \mathrm{bp}$ upstream to $500 \mathrm{bp}$ downstream of transcription start sites (TSS).

We assayed acetylation at TSS of the four subsets of genes involved in the early transcriptional response, namely rapidly up or down and delayed up or down (Fig. 2). A striking initial finding was that genes involved in the progressive transcriptional response, had high basal acetylation levels. This was irrespective of the direction of transcriptional change adopted in response to HDACi (Fig. 4). In contrast, levels of H3K27me3 prior to treatment were close to the median for three of the four categories of responding genes (Fig. 4). The exception was genes that were up-regulated after a delay, which had relatively high levels of H3K27me3 in untreated cells. It is interesting that for this category of genes, levels of acetylation at all three histone lysines tested, were lower (though still well above the untreated median) than for the other three categories of responding genes (Fig. 4). Changes in acetylation following exposure to $\mathrm{HDACi}$, were small. Genes that were up-regulated, whether immediately or with a delay, showed, on average, a gradual, progressive increase in H4K16ac (Fig. 5). For the same categories of up-regulated genes, H3K9ac and H3K27ac increased slightly after $30 \mathrm{~min}$, but then remained unchanged for the rest of the time-course.

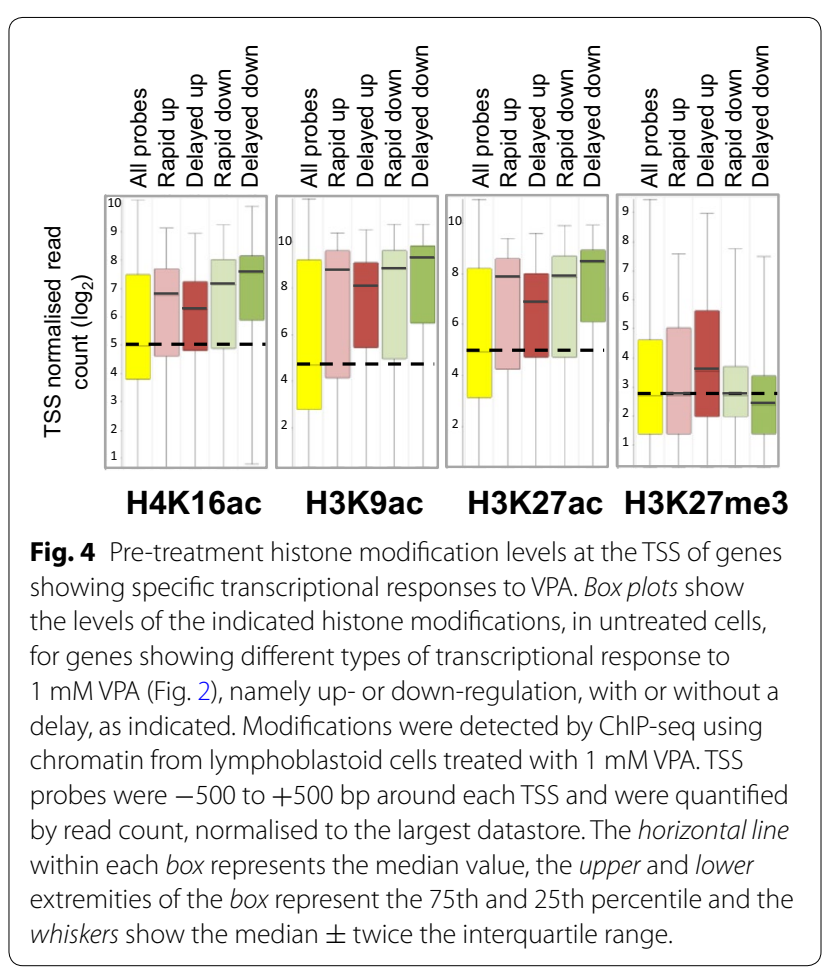


Down-regulated genes showed no change in H3K9ac or $\mathrm{H} 3 \mathrm{~K} 27 \mathrm{ac}$ across the entire time-course and just a small and transient reduction in H4K16ac at 30 min (Fig. 5). Thus, changes in histone acetylation at the TSS of persistently responding genes are small, associated almost exclusively with up-regulated genes and tend to occur soon (30 min) after addition of the inhibitor.

Unexpectedly, the most dramatic change in histone modification in response to HDACi was in levels of H3K27me3, a modification put in place by the Polycomb silencing complex PRC2 [59]. A strong increase in H3K27me3 at TSS was first detected at 60 min and persisted at $120 \mathrm{~min}$ (Fig. 6a). This change was detectable across all genes (Fig. 6a, "All Probes"), and was independent of the manner in which transcription was altered by HDACi (Fig. 6a). We analysed the genomic distribution of the change in H3K27me3 with 1,000 bp rolling window probes. The increase in $\mathrm{H} 3 \mathrm{~K} 27 \mathrm{me} 3$ after $60 \mathrm{~min}$ was seen only in windows which included TSS and not in regions classed as non-TSS or in windows overlapping other genomic features (Fig. 6b). All four sets of persistently responding genes revealed by SOTA showed increased levels of H3K27me3 at $t_{60}$ and $t_{120}$, but no change at $t_{30}$.

The most likely explanation for HDACi-induced increase in H3K27me3 specifically at TSS, is that levels of catalytically active PRC2 have increased at TSS. This

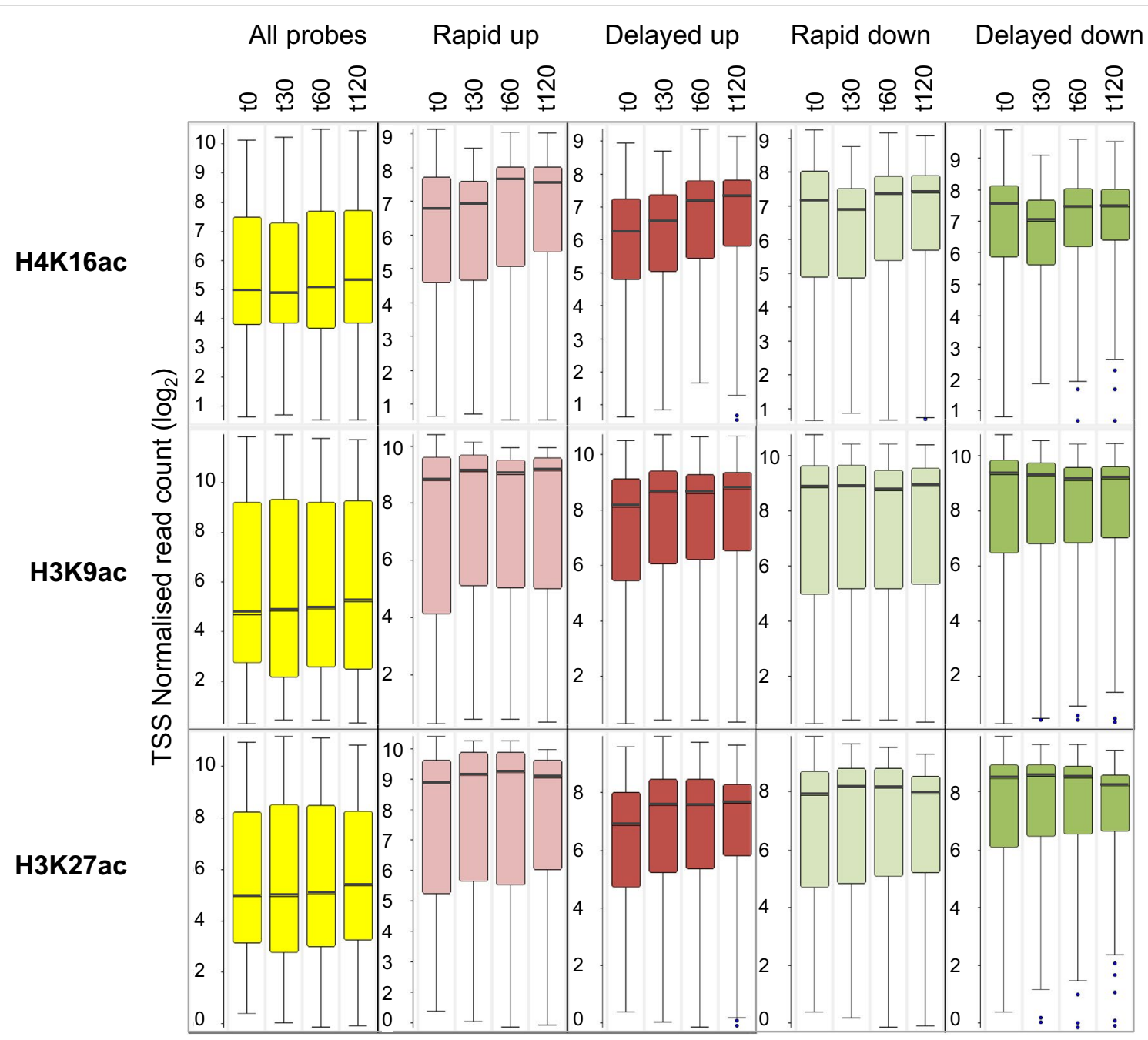

Fig. 5 Changes over time in histone acetylation at the TSS of genes showing specific transcriptional responses to VPA. ChIP-seq was carried out on lymphoblastoid cells treated for 0, 30,60 and 120 min with $1 \mathrm{mM} \mathrm{VPA}$ using antibodies to one of three different acetylated histones, as indicated. Changes over time are shown for each of the four categories of persistently responding genes (Fig. 2), as indicated. Box plots, configured as in Fig. 4, show the distribution of normalised read counts at the TSS of genes that showed significantly altered transcript levels at each time point. TSS probes were -500 to $+500 \mathrm{bp}$ around each TSS and were quantified by read count quantitation, normalised to the largest datastore. 
in turn could be attributed, for some genes at least, to spreading of PRC2 from adjacent, PRC2-rich, regions. Examination of genes with blocks of H3K27me3 adjacent to the TSS was consistent with this. Figure $6 \mathrm{c}$ shows a screenshot of the NBPF15 gene: H3K27me3 can be seen to spread over the TSS 60 min after addition of HDACi. In contrast, the distribution of $\mathrm{H} 3 \mathrm{~K} 27 \mathrm{ac}$ in the gene body shows no sign of spreading (Fig. 6c), in line with the general lack of effect of HDACi on acetylation of chromatin at and around TSS (Fig. 5). We note that, in the treated cell population, the TSS contains both H3K27me3 and H3K27ac. This could be due to the existence of separate cell populations (i.e. with either methylated or acetylated TSS) or to the presence of both modifications on the same chromatin fragment. Further experimentation using this model system should allow this interesting issue to be resolved for specific TSS.

\section{Inhibition of the EZH1/2 methyltransferases modifies the transcriptional response to VPA}

To explore the possible involvement of EZH2 activity in establishing the transcriptional response to HDACi, we used UNC1999 [60, 61], an inhibitor of both EZH2 and its close homologue EZH1. Inhibition of both enzymes is important in view of evidence from mouse knockout studies that EZH1 can substitute for EZH2 to maintain PRC2 function [32, 62]. We tested transcriptional change after treating for 120 min with $1 \mathrm{mM}$ VPA alone, $3 \mu \mathrm{M}$ UNC1999 alone and VPA + UNC1999. At $3 \mu \mathrm{M}$, UNC1999 led to a progressive reduction in global levels of H3K27me3 (Fig. 7a) but had no effect on cell viability, either alone or in combination with $1 \mathrm{mM}$ VPA (Additional file 7). It should be noted that the reduction in global levels of H3K27me3 was slow, occurring over days. Effects observed after only $120 \mathrm{~min}$ are likely to be due to the inhibition of de novo H3K27 tri-methylation at specific loci rather than a general reduction in H3K27me3 levels. UNC1999 on its own had a small transcriptional effect after $120 \mathrm{~min}$ (32 genes up, 31 down) but had a significant effect on the transcriptional response to VPA. The numbers of genes up- and down-regulated by VPA and UNC1999 are shown in Fig. 7. Of 362 genes downregulated by VPA in this experiment, 147 (41\%) were UNC1999 sensitive (i.e. their down-regulation was prevented by UNC1999), while 215 (59 \%) were UNC1999 insensitive. These two populations had different ontologies (Additional file 8). Cytokine and apoptosis-related genes were UNC1999 sensitive (EZH2 dependent), while genes involved in transcriptional regulation and, importantly, KAT complex genes, were UNC1999 insensitive (EZH2 independent). Ninety-three genes were downregulated only by VPA plus UNC, indicating that their ability to respond to VPA is normally suppressed by
PRC2-mediated H3K27 methylation. Of 643 genes upregulated by VPA in this experiment, 341 (53 \%) were UNC1999 sensitive (EZH2 dependent) and 302 (47 \%) were UNC1999 insensitive (EZH2 independent). As with down-regulated genes, the ontologies of the two groups differed, with transcription related terms again confined to the UNC1999 insensitive group. Developmental terms were found in both groups, but were much more prominent amongst UNC1999 sensitive (EZH2 dependent) genes (Fig. 7b). A relatively small number of genes, 59 , were up-regulated only by VPA plus UNC, indicating that their up-regulation by VPA is normally suppressed by PRC2.

These results show that ongoing EZH1/2 activity is essential for the VPA-induced change in expression of some categories of gene. Surprisingly, the results show that EZH1/2 can be required for either activation or silencing, depending on the genes involved. We used ChIP data to ask whether the effects of EZH1/2 inhibition were influenced by the H3K27 modification status prior to treatment, but found little evidence for this. Genes whose transcription was changed (up or down) by UNC1999 alone had relatively low levels of H3K27ac and high levels of H3K27me3, indicating silenced or lowly expressed genes (Fig. 7c). Apart from this, all VPAresponsive genes, irrespective of their EZH1/2 dependence, had levels of H3K27ac above the population median and levels of H3K27me3 close to the median (Fig. 7c).

\section{Discussion}

\section{Adaptive strategies}

We have shown that the transcriptional response that develops during the first $2 \mathrm{~h}$ of exposure to HDACi involves a restricted number of genes, largely within specific functional categories. These categories indicate a coordinated transcriptional response that allows the cell, first, to survive, and then to adapt to life in the presence of HDACi. A prominent feature of the early HDACi response is the universal down-regulation of genes encoding KAT complex components. This will mitigate the hyperacetylation induced by HDACi, and explains both the return to normal levels of acetylation after prolonged culture in HDACi (e.g. [63]) and the very early finding that histone acetylation levels fell rapidly to below pre-treatment levels when HTC cells were released from prolonged butyrate inhibition [17].

Other gene sets with characteristic patterns of transcriptional change provide additional clues to the nature of the adaptive response. The rapidly and consistently down-regulated cytokine category was particularly enriched in genes involved in growth control, such as GDF9 and its paralogue GDF15. GDF9 is necessary for cell cycle progression, mediating 


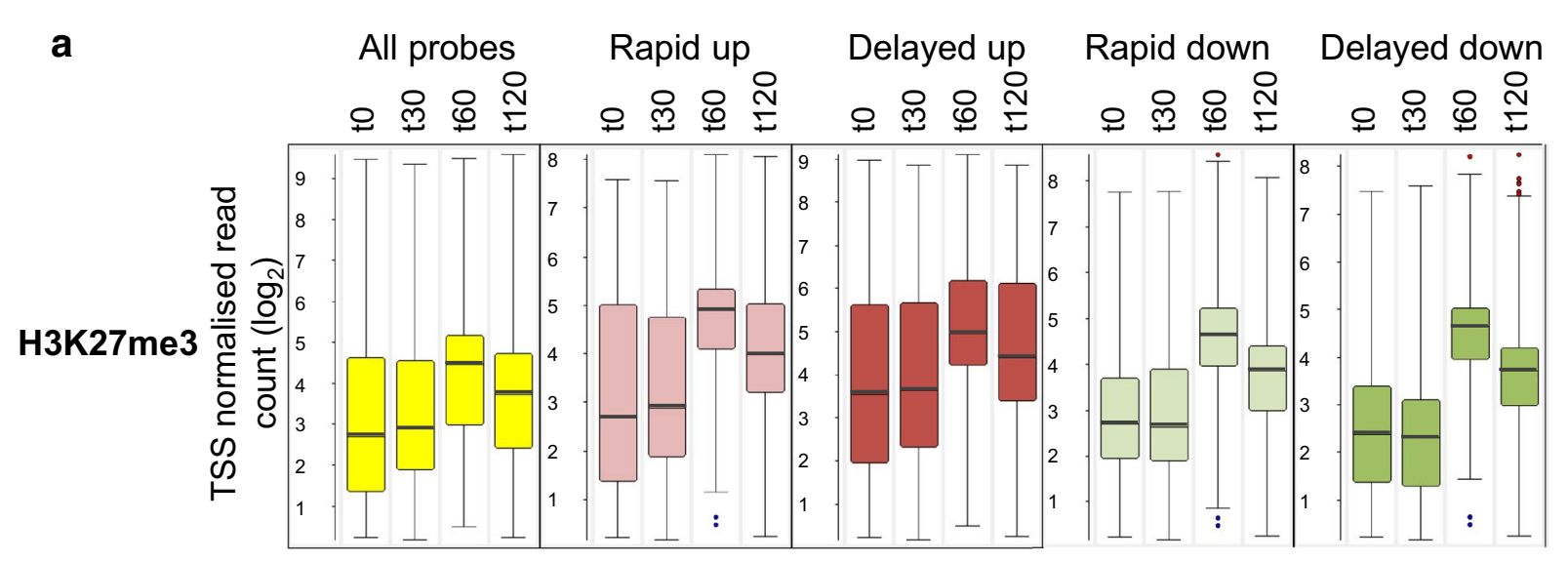

b
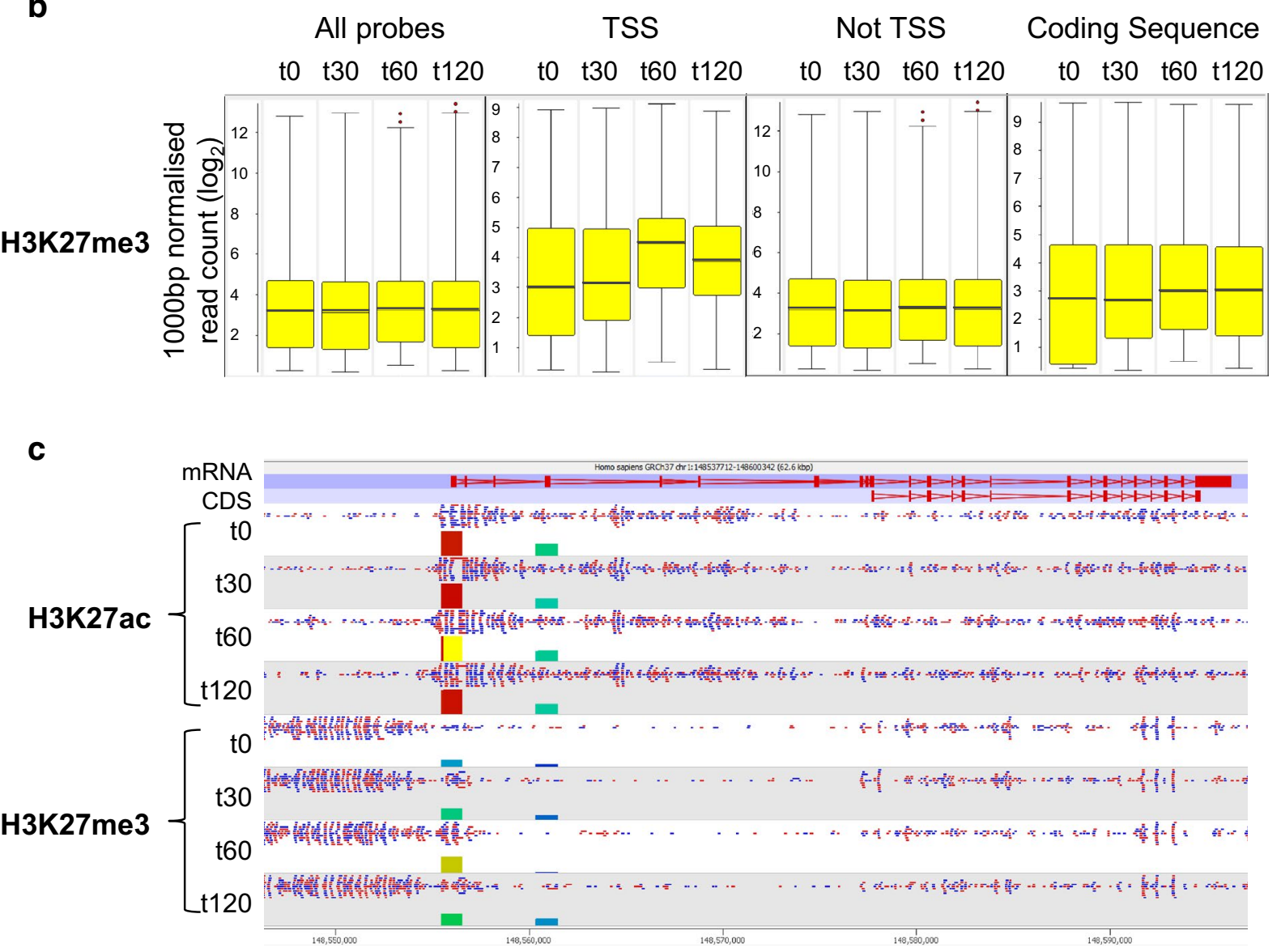

Fig. 6 Changes over time in H3K27 tri-methylation at the TSS of genes showing specific transcriptional responses to VPA and at other genomic regions. a Levels of H3K27me3, after increasing time in $1 \mathrm{mM} \mathrm{VPA}$, at the TSS of genes involved in the four categories of persistent transcriptional response (Fig. 2), as indicated. TSS probes were -500 to $+500 \mathrm{bp}$ around each TSS and were quantified by read count, normalised to the largest datastore. $\mathbf{b}$ Levels of H3K27me3, after increasing time in $1 \mathrm{mM} \mathrm{VPA}$, at different genomic regions. 1,000 bp rolling windows were quantified by read count quantitation, normalised to the largest datastore. The distribution of all probes and those overlapping with TSS, not overlapping with TSS or overlapping coding sequence are shown. c Screenshot from SeqMonk showing changes in H3K27me3 and H3K27ac at and around the TSS of the NBPF15 gene. The positions of the gene and the coding sequence are indicated across the top of the panel. Forward reads are shown in red and reverse in blue. The coloured boxes below each data track show the position and value (box height) of each TSS probe. 
a

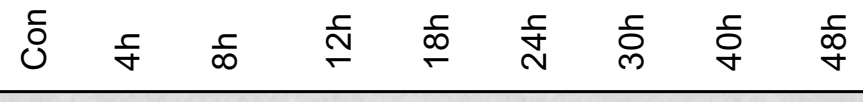

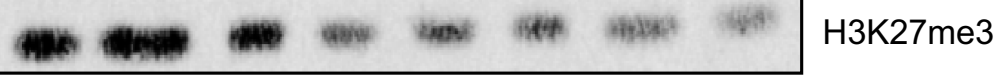

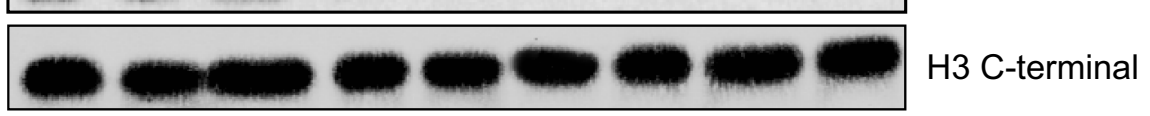

b
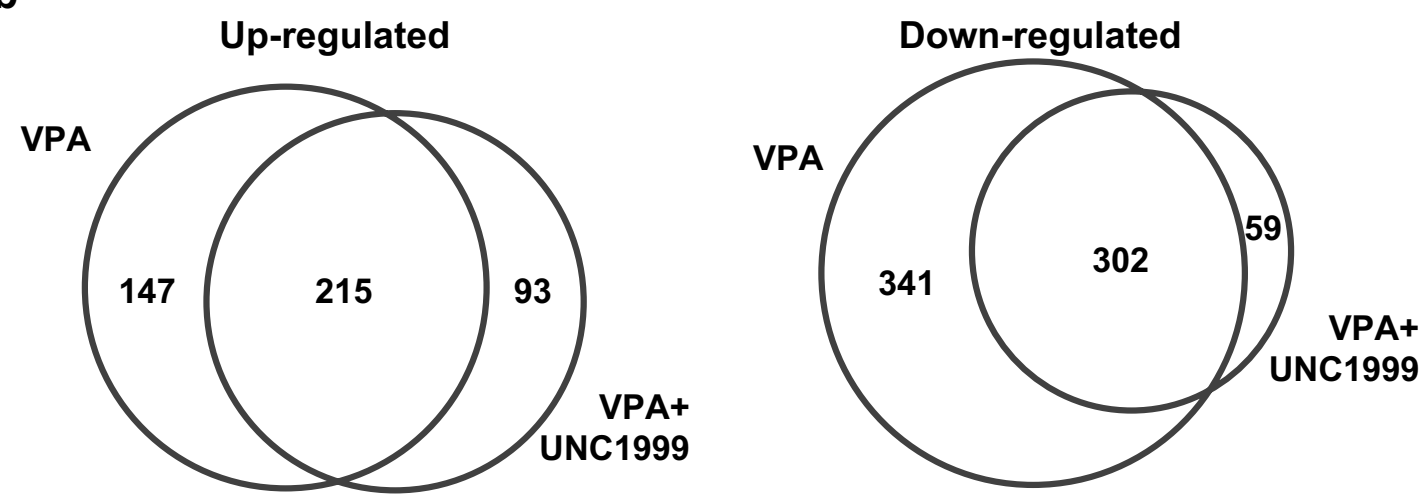

C

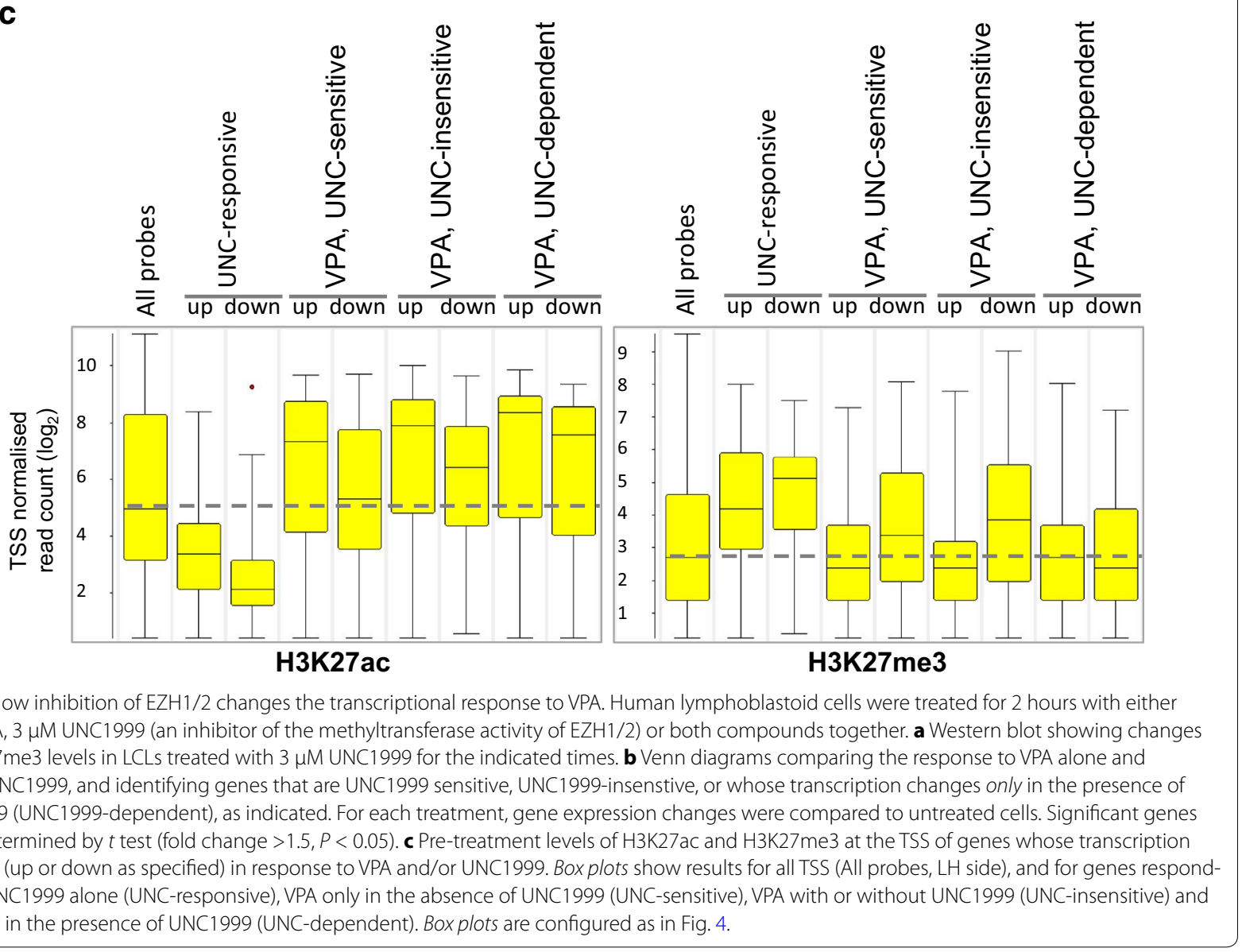

Fig. 7 How inhibition of EZH1/2 changes the transcriptional response to VPA. Human lymphoblastoid cells were treated for 2 hours with either $1 \mathrm{mMVPA}, 3 \mu \mathrm{M}$ UNC1999 (an inhibitor of the methyltransferase activity of EZH1/2) or both compounds together. a Western blot showing changes in H3K27me3 levels in LCLs treated with $3 \mu \mathrm{M}$ UNC1999 for the indicated times. b Venn diagrams comparing the response to VPA alone and VPA + UNC1999, and identifying genes that are UNC1999 sensitive, UNC1999-insenstive, or whose transcription changes only in the presence of UNC1999 (UNC1999-dependent), as indicated. For each treatment, gene expression changes were compared to untreated cells. Significant genes were determined by $t$ test (fold change $>1.5, P<0.05$ ). c Pre-treatment levels of H3K27ac and H3K27me3 at the TSS of genes whose transcription changes (up or down as specified) in response to VPA and/or UNC1999. Box plots show results for all TSS (All probes, LH side), and for genes responding to UNC1999 alone (UNC-responsive), VPA only in the absence of UNC1999 (UNC-sensitive), VPA with or without UNC1999 (UNC-insensitive) and VPA only in the presence of UNC1999 (UNC-dependent). Boxplots are configured as in Fig. 4. 
both the G1-S transition and passage through G2-M [56]. GDF9/GDF15 down-regulation may explain the slowed growth and G1 and G2M blocks caused by HDACi in LCLs (Additional file 1A) and other cell types [64]. Slowed growth will protect the cell against long-term genome damage caused by replicative stress through S-phase and chromosome mis-segregation at mitosis.

In order to function and grow (albeit slowly) in the presence of HDACi, the cell must establish a new pattern of gene expression supported by a modified epigenome. Our results show down-regulation of genes potentially involved in determining the lymphoid phenotype of the LCL, such as interleukins and alpha interferons and up-regulation of genes required for a change of phenotype, including homeobox genes and components of the Wnt and Notch signalling pathways. This change need not involve complete loss of the original lymphoid phenotype, or differentiation along a pre-defined lineage, and we see no evidence for this. Indeed, there are likely to be many different epigenomes and transcriptomes that are compatible with survival and growth in the presence of HDACi. The changes we observe increase the chances of one of these states being reached by any single cell. Longer term, cells whose modified transcriptomes allow them to cope most effectively with the prevailing environment, will come to dominate the cell population through normal selection processes.

\section{The evolutionary necessity of an adaptive response to $\mathrm{HDACi}$}

Many HDACi are natural products, usually produced by bacteria, and are widely present in the environments encountered by eukaryotic cells $[65,66]$. Shortchain fatty acids are common products of bacterial metabolism and are present at $\mathrm{mM}$ concentrations in the large intestines of humans and other mammals [67, 68]. HDACi such as Trichostatin A, Trapoxin and Depsipeptide, are bacterial antimicrobials that kill eukaryotic micro-organisms (such as Aspergillus) competing for the same resources [69]. Killing of competitors and predation are common in microbial communities [70]. Over vast periods of evolutionary time since their first emergence, eukaryotes must have evolved strategies to protect themselves, and their uniquely eukaryotic chromatin-based epigenetic systems, from HDACi secreted by competing prokaryotes. This evolutionary background, and the fact that humans and other higher eukaryotes continue to be exposed to environmental HDACi [68], provides a convincing rationale for the existence of the protective response uncovered by our experiments.

\section{Histone modifications as determining factors in the transcriptional response to $\mathrm{HDACi}$}

Our results show that the way in which genes initially respond to HDACi is closely associated with their histone modification status prior to treatment. Genes that are rapidly up- or down-regulated, some of which form part of the proposed adaptive response, are marked by high levels of $\mathrm{H} 3$ and $\mathrm{H} 4$ acetylation, even though their transcript levels are close to the population mean. Following HDACi treatment, despite the rapid increase in histone acetylation detected by Western blotting, changes in acetylation at and around TSS were modest at best, and often absent. This can be attributed, in part to the initially high levels of histone acetylation of HDACi-responsive genes, but still indicates that increased histone acetylation is not an immediate driver of the transcriptional changes we detect. It seems that high levels of histone acetylation provide a chromatin context that allows genes to change their transcription level (up- or down-) in response to the appropriate signals.

Unexpectedly, the most striking change in histone modification over the first $120 \mathrm{~min}$ of treatment with $\mathrm{HDACi}$, was an increase in H3K27me3 at TSS. We detected no increase in transcripts encoding PRC2 core components, and it seems likely that our findings reflect the redistribution of existing PRC2 complexes to TSS [71]. The processes by which PRC2 is directed to its target sites, and by which it is retained there, are complex and still incompletely understood [72, 73]. H3K27me3 is necessary for stable PRC2 binding and maintenance of silencing [74]. H3K27 methylation can be blocked by pre-existing acetylation of the same residue, and this modification is antagonistic to silencing [30, 32]. In view of this, it is interesting that we were able to show that blocks of H3K27ac extending from the gene body into the TSS did not prevent the spreading of H3K27me3 into the TSS from enriched upstream regions. Within treated populations, the nucleosome at the TSS contained both acetylated and/or tri-methylated H3K27. While it is theoretically possible that the two different $\mathrm{H} 3$ modifications are carried on a single nucleosome [75], it is more likely that that result reflects a mixed population of cells, with some having H3K27me3 on the single TSS nucleosome and others H3K27ac. It is clear that VPA does not induce any detectable spreading or enhancement of blocks of H3K27ac, in line with its modest effects on gene-proximal histone acetylation in general.

\section{The role of Polycomb mediated gene regulation}

Phosphorylation of $\mathrm{H} 3$ at serine 28 , catalysed by MSK1/2, can displace PRC2, presumably by disrupting binding to the adjacent, methylated residue [76, 77]. H3S28ph levels have been shown to increase 
at the promoter regions of a specific subset of genes that are transcriptionally activated when quiescent 3 T3 cells are stimulated back into growth [78]. This allows Polycomb-silenced genes to be reactivated without the need to demethylate H3K27. This finding is relevant to our results in that the antibody to H3K27me3 used for these experiments, while highly specific for methylated H3K27 in peptide binding assays, binds only weakly to peptides that are also phosphorylated at K28 [79]. Thus, it is possible that the increased, TSS-specific antibody binding that occurs after $60 \mathrm{~min}$ exposure to $\mathrm{HDACi}$, reflects unmasking of pre-existing H3K27me3 by de-phosphorylation of H3K27me3S28ph. We cannot discount this possibility, but regard it as unlikely, not least because the precisely timed increase in H3K27me3 that we observe occurs at TSS, irrespective of their transcriptional status, contrary to the selective phosphorylation of H3S28 at active TSS [78]. However, the functional outcome will be the same in each case, namely enhanced gene silencing through H3K27me3mediated binding of PRC2.

Surprisingly, genes that were either up- or downregulated over the first $120 \mathrm{~min}$ were distinguished from one another not by $\mathrm{H} 3 / \mathrm{H} 4$ acetylation, which was high for both, but by H3K27me3, which was elevated, in untreated cells, only for genes up-regulated following a delay. Genes that carry a combination of histone modifications normally associated with active or silent chromatin states were first identified in embryonic cells $[80,81]$. These "bivalent" genes were shown to correspond largely to genes that were poised to respond to developmental signals [80-83]. It may be that HDACi selectively activate such poised, bivalent genes. This is consistent with our ontology analysis which shows enrichment of up-regulated genes in terms relating to transcriptional regulation and development. We also note that the regulatory effects of PRC2 can be modulated by histone modifications associated with active chromatin, such as H3K4me3 [31], raising the possibility that PRC2 effects might differ depending on levels of histone acetylation.

\section{Conclusions}

Cells respond to HDACi with a transcription based, adaptive response that allows them to survive in the presence of the inhibitor. The response includes the universal down-regulation of KAT complex components, a change that will diminish and eventually eliminate protein hyperacetylation caused by HDAC inhibition, and the up-regulation of developmental regulators that adjust transcription to accommodate inhibitor-induced epigenomic changes. Genes whose expression is sensitive to HDACi are consistently premarked by high levels of $\mathrm{H} 3$ and $\mathrm{H} 4$ acetylation. We find little evidence that transcriptional changes are driven by further increases in histone acetylation at gene control regions, but there is a dramatic, acrossthe-board increase in $\mathrm{H} 3 \mathrm{~K} 27 \mathrm{me} 3$ at transcription start sites. Inhibition of the methyltransferase EZH1/2 alters the transcriptional response, confirming the functional involvement of the Polycomb complex PRC2. Collectively, our results support the conclusion that the transcriptional response to $\mathrm{HDACi}$, including activation or mobilisation of PRC2, is driven by increased acetylation of specific non-histone proteins, with histone acetylation providing a chromatin context that allows transcriptional change. Given the potential importance of the survival response in determining the resistance or sensitivity of cancer cells to therapeutic doses of $\mathrm{HDACi}$, the identification of these proteins is a key objective.

\section{Methods \\ Cell culture}

The work described here used two long-established human lymphoblastoid cell lines (LCL), GM12878 (Coriell Institute, see [28]) and AH-LCL (produced inhouse in the course of previous work by Rowe and colleagues [84]). Lines were maintained at $37{ }^{\circ} \mathrm{C}, 5 \% \mathrm{CO}_{2}$ in RPMI 1640 medium, 10 \% foetal bovine serum, supplemented with L-glutamine $(2 \mathrm{mM})$ and penicillin/ streptomycin (all reagents from Life Technologies). A stock solution of sodium valproate (VPA, Sigma) was prepared at $1 \mathrm{M}$ in water and stocks of suberoylanilide hydroxamic acid (SAHA, Sigma) were prepared at 0.5, 2.5 and 12.5 in DMSO. Cells were treated at $0.2,1$ and $5 \mathrm{mM}$ VPA and 0.5, 2.5 and $12.5 \mu \mathrm{M}$ SAHA such that DMSO concentration in SAHA-treated cells was always $0.1 \%$. A stock solution of UNC1999 was prepared at $3 \mathrm{mM}$ in DMSO and cells were treated with $3 \mu \mathrm{M}$ UNC1999.

\section{Antibodies}

Rabbit polyclonal antisera to H4K16ac (R251), H3K9ac (R607) and H3K4me3 (R612) were raised in-house by immunisation with synthetic peptides conjugated to ovalbumin as previously described [85]. The antibody to H3K27me3 was from Millipore (07-449) and to H3K27ac from Abcam (ab4729). Antibody specificities was assayed by inhibition ELISA and checked by Western blotting.

\section{Western blotting}

Histones were extracted from ES cells by acid extraction and analysed by electrophoresis in $15 \%$ 
SDS-polyacrylamide gels and western blotting as previously described [4]. Protein loading was confirmed by Ponceau $S$ staining before proteins were probed with appropriate primary antibodies. Primary antibody binding was detected by fluorescent-tagged anti-rabbit IgG secondary antibody (Rockland) and detected by scanning (Odyssey system; LI-COR, Cambridge, UK).

\section{FACS cell cycle analysis}

Treated and control cells were washed in PBS and fixed in ice cold $90 \%$ ethanol at $-20{ }^{\circ} \mathrm{C}$ for at least $30 \mathrm{~min}$. Fixed cells were washed in PBS and resuspended in propidium iodide staining buffer [PBS with $20 \mu \mathrm{g} / \mathrm{ml}$ propidium iodide (Sigma), $100 \mu \mathrm{g} / \mathrm{ml}$ RNase A (Life Technologies), $0.1 \% \mathrm{NP} 40,5 \mu \mathrm{g} / \mathrm{ml}$ tri-sodium citrate (Sigma), $5 \%$ foetal bovine serum (Life Technologies) and $0.02 \%$ sodium azide (Sigma)]. Cells were analysed on a Cyan ADP Flow Cytometer using Summit software v4.3 (Beckman Coulter), gating for forward and side scatter and pulse width to isolate single cells. Apoptotic populations in untreated or treated LCLs were determined using the Annexin V Apoptosis Detection Kit-APC (eBioscience) according to the manufacturer's instructions.

\section{Microarray expression analysis}

All microarray experiments were carried out in biological triplicates. All microarray reagents are from Roche Nimblegen unless otherwise stated. Cells were harvested by centrifugation and RNA was extracted and purified using the RNeasy kit with DNase digestion (Qiagen) according to the manufacturer's instructions. Double stranded cDNA was synthesised using the cDNA Synthesis System, including RNase I and Proteinase $\mathrm{K}$ treatment followed by DNA clean up using the PCR purification kit (Qiagen). Samples were labelled with cy3 using a Nimblegen One-Colour Labeling Kit, mixed with alignment oligos and sample tracking control oligos (Nimblegen Hybridisation and Sample Tracking Control Kits) and hybridised to a $12 \times 135 \mathrm{k}$ HD2 expression array (Roche Nimblegen, containing 3 probes per sequence for 44,049 human sequences) and scanned on a Nimblegen MS200 Microarray scanner. Data were extracted using DEVA (Roche Nimblegen) and normalised by robust multichip average in R. Direct comparisons of $t_{0}$ and individual time points was carried out using $t$ Tests. Genes with a $P$ value smaller than 0.05 and FC larger than 1.5 have been selected for further analysis including functional annotation and network construction. The ongoing transcriptional response was identified using ANOVA in TMEV [86]. The $P$ values derived from ANOVA analysis were corrected for multiple testing by performing the Benjamini-Hochberg correction in R. Differentially expressed genes were selected using a threshold of false discovery rate (FDR) smaller than $10 \%$ with fold change greater than 1.5 . In order to group genes with similar expression patterns into clusters, a SOTA analysis was performed using TMEV [86]. Each cluster that was characterised by highly co-regulated genes was then functionally annotated for GO terms using the web based tool DAVID [55]. Co-regulation networks were constructed using ARACNE and visualised in Cytoscape with a forced directed layout. The microarray data from this publication have been submitted to the GEO database (http:// www.ncbi.nlm.nih.gov/geo/) and assigned the identifier GSE65297.

\section{Chromatin immunoprecipitation: sequencing}

Immunoprecipitation of native chromatin was performed based on the method described previously [87]. Briefly, cells were lysed to release nuclei prior to micrococcal nuclease digestion. The amount of micrococcal nuclease added and digestion time were adjusted to obtain a mix of mono- and short oligo-nucleosomes, optimal for immunoprecipitation. Chromatin was precleared by incubation with protein A Sepharose beads and incubated overnight with antibodies to H4K16ac, H3K9ac, H3K27ac and H3K27me3. Antibody-bound material was isolated on Protein A-Sepharose beads (Invitrogen, UK) and DNA from antibody-bound and input chromatin was purified by PCR purification kit (Qiagen). Sequencing libraries were prepared from 100 ng DNA per sample using the KAPA Library preparation kit for Illumina (Anachem). Samples were barcoded using the system described by Bronner et al. [88]. Sequencing was carried out at the West Midlands Regional Genetics Laboratory. Pooled libraries were clustered using a 'cBot' cluster generation system at a final concentration of $13 \mathrm{pM}$, followed by sequencing on a HiSeq 2500, in 'rapid run', paired-end mode $(2 \times 51 \mathrm{bp})$. FASTQ files were simultaneously generated and de-multiplexed using the Illumina 'HiSeq Analysis software' v0.9 followed by alignment using Bowtie2 [89]. Bowtie2 was run using the default parameters for 'very-sensitive-local' alignment mode. Crucially, this means the 'best alignment' is reported for every read that can be mapped; if there are two alignments that are tied, then one is randomly chosen. The output from Bowtie2 was converted to bam files and sorted using Samtools v0.1.19. ChIP-seq data was analysed using SeqMonk (Babraham Institute, http://www.bioinformatics.babraham.ac.uk/projects/ seqmonk/). 


\section{Additional files}

Additional file 1: The global changes in histone modification and cell cycle profile in cells treated with HDACi.

Additional file 2: SOTA and ontological analysis of the transcriptional response to $5 \mathrm{mMVPA}, 0.5 \mu \mathrm{M}$ SAHA and $12.5 \mu \mathrm{M}$ SAHA.

Additional file 3: The characteristics of genes responding to $0.2 \mathrm{mM}$ VPA.

Additional file 4: All genes responding significantly to $0.2 \mathrm{mM} \mathrm{VPA.}$

Additional file 5: Genes that are down-regulated by HDACi and are involved in "cytokine activity".

Additional file 6: A table showing "pattern specification process genes" that are up-regulated by HDACi treatment.

Additional file 7: The effect on the cell cycle and apoptosis of VPA and UNC 1999 treatment

Additional file 8: Ontology analysis of VPA-responsive genes based on their sensitivity to UNC1999.

\section{Authors' contributions}

JAH devised and performed laboratory experiments, analysed the data and wrote the paper. NT analysed the data. MW performed experiments. BMT devised experiments, discussed the data and wrote the paper. All authors read and approved the manuscript.

\section{Acknowledgements}

We are grateful to Paul Marks for sending us the SAHA used for our first experiments, Samuel Clokie, WMRGL, for assistance with Hi-Seq DNA sequencing and Simon Andrews and the bioinformatics team at the Babraham Institute for introducing us to SeqMonk. We thank Peter Cockerill, Padma-Sheela Jayaraman and Karl Nightingale for critical reading of early versions of the manuscript. This work was supported by project Grants from Cancer Research UK.

\section{Compliance with ethical guidelines}

\section{Competing interests}

The authors declare that they have no competing interests.

Received: 18 May 2015 Accepted: 3 August 2015

Published online: 16 September 2015

\section{References}

1. Johnsson A, Durand-Dubief $M$, Xue-Franzén $Y$, Rönnerblad $M$, Ekwall K, Wright A. HAT-HDAC interplay modulates global histone H3K14 acetylation in gene-coding regions during stress. EMBO Rep. 2009;10:1009-14

2. Marmorstein R, Trievel RC. Histone modifying enzymes: structures, mechanisms, and specificities. Biochim Biophys Acta. 2009;1789:58-68.

3. Covault J, Chalkley R. The identification of distinct populations of acetylated histone. J Biol Chem. 1980;255:9110-6.

4. Nightingale KP, Gendreizig S, White DA, Bradbury C, Hollfelder F, Turner BM. Cross-talk between histone modifications in response to histone deacetylase inhibitors: MLL4 links histone $\mathrm{H} 3$ acetylation and histone H3K4 methylation. J Biol Chem. 2007:282:4408-16.

5. Ekwall K. Genome-wide analysis of HDAC function. Trends Genet. 2005:21:608-15.

6. Kasper LH, Qu C, Obenauer JC, McGoldrick DJ, Brindle PK. Genomewide and single-cell analyses reveal a context dependent relationship between CBP recruitment and gene expression. Nucleic Acids Res. 2014:42:11363-82.

7. Wang Z, Zang C, Cui K, Schones DE, Barski A, Peng W, et al. Genome-wide mapping of HATs and HDACs reveals distinct functions in active and inactive genes. Cell. 2009;138:1019-31.
8. Bernstein BE, Mikkelsen TS, Xie X, Kamal M, Huebert DJ, Cuff J, et al. A bivalent chromatin structure marks key developmental genes in embryonic stem cells. Cell. 2006;125:315-26.

9. Weake VM, Dyer JO, Seidel C, Box A, Swanson SK, Peak A, et al. Posttranscription initiation function of the ubiquitous SAGA complex in tissue-specific gene activation. Genes Dev. 2011;25:1499-509.

10. Fan J, Krautkramer KA, Feldman JL, Denu JM. Metabolic regulation of histone post-translational modifications. ACS Chem Biol. 2015;10:95-108.

11. Kouzarides T. Chromatin modifications and their function. Cell. 2007;128:693-705.

12. Nightingale KP, O'Neill LP, Turner BM. Histone modifications: signalling receptors and potential elements of a heritable epigenetic code. Curr Opin Genet Dev. 2006;16:125-36.

13. Oliver SS, Denu JM. Dynamic interplay between histone $\mathrm{H} 3$ modifications and protein interpreters: emerging evidence for a "histone language". ChemBioChem. 2011;12:299-307.

14. Turner BM. Defining an epigenetic code. Nat Cell Biol. 2007;9:2-6.

15. Turner BM. The adjustable nucleosome: an epigenetic signaling module Trends Genet. 2012;28:436-44

16. Allegra P, Sterner R, Clayton DF, Allfrey VG. Affinity chromatographic purification of nucleosomes containing transcriptionally active DNA sequences. J Mol Biol. 1987;196:379-88.

17. Covault J, Perry M, Chalkley R. Effects of histone hyperacetylation and hypoacetylation on RNA synthesis in HTC cells. J Biol Chem. 1982;257:13433-40.

18. Johnson EM, Sterner R, Allfrey VG. Altered nucleosomes of active nucleolar chromatin contain accessible histone $\mathrm{H} 3$ in its hyperacetylated forms. J Biol Chem. 1987;262:6943-6.

19. Kurdistani SK, Tavazoie S, Grunstein M. Mapping global histone acetylation patterns to gene expression. Cell. 2004;117:721-33.

20. Kellis M, Wold B, Snyder MP, Bernstein BE, Kundaje A, Marinov GK, et al. Defining functional DNA elements in the human genome. Proc Natl Acad Sci USA. 2014;111:6131-8.

21. Schübeler D, MacAlpine DM, Scalzo D, Wirbelauer C, Kooperberg C, van Leeuwen $F$, et al. The histone modification pattern of active genes revealed through genome-wide chromatin analysis of a higher eukaryote. Genes Dev. 2004;18:1263-71.

22. Roh T-Y, Cuddapah S, Zhao K. Active chromatin domains are defined by acetylation islands revealed by genome-wide mapping. Genes Dev. 2005; 19:542-52.

23. Roh T, Wei G, Farrell CM, Zhao K. Genome-wide prediction of conserved and nonconserved enhancers by histone acetylation patterns. Genome Res. 2006:17:74-81.

24. Verdin E, Ott M. 50 years of protein acetylation: from gene regulation to epigenetics, metabolism and beyond. Nat Rev Mol Cell Biol. 2014;16:258-64.

25. Gelbart ME, Larschan E, Peng S, Park PJ, Kuroda MI. Drosophila MSL complex globally acetylates H4K16 on the male X chromosome for dosage compensation. Nat Struct Mol Biol. 2009;16:825-32.

26. Turner BM, Birley AJ, Lavender J. Histone $\mathrm{H} 4$ isoforms acetylated at specific lysine residues define individual chromosomes and chromatin domains in Drosophila polytene nuclei. Cell. 1992;69:375-84.

27. Taylor GCA, Eskeland R, Hekimoglu-Balkan B, Pradeepa MM, Bickmore WA. H4K16 acetylation marks active genes and enhancers of embryonic stem cells, but does not alter chromatin compaction. Genome Res. 2013;23:2053-65.

28. Dunham I, Kundaje A, Aldred SF, Collins PJ, Davis CA, Doyle F, et al. An integrated encyclopedia of DNA elements in the human genome. Nature. 2012:489:57-74.

29. Jin $Q$, Yu L-R, Wang L, Zhang Z, Kasper LH, Lee J-E, et al. Distinct roles of GCN5/PCAF-mediated H3K9ac and CBP/p300-mediated H3K18/27ac in nuclear receptor transactivation. EMBO J. 2011;30:249-62.

30. Pasini D, Malatesta M, Jung HR, Walfridsson J, Willer A, Olsson L, et al. Characterization of an antagonistic switch between histone $\mathrm{H} 3$ lysine 27 methylation and acetylation in the transcriptional regulation of Polycomb group target genes. Nucleic Acids Res. 2010;38:4958-69.

31. Schmitges FW, Prusty AB, Faty M, Stützer A, Lingaraju GM, Aiwazian J, et al. Histone methylation by PRC2 is inhibited by active chromatin marks. Mol Cell. 2011:42:330-41. 
32. Boudadi E, Stower H, Halsall JA, Rutledge CE, Leeb M, Wutz A, et al. The histone deacetylase inhibitor sodium valproate causes limited transcriptional change in mouse embryonic stem cells but selectively overrides Polycomb-mediated Hoxb silencing. Epigenetics Chromatin. 2013;6:11.

33. Hezroni H, Sailaja BS, Meshorer E. Pluripotency-related, valproic acid (VPA)-induced genome-wide histone H3 lysine 9 (H3K9) acetylation patterns in embryonic stem cells. J Biol Chem. 2011;286:35977-88.

34. Evason K, Collins JJ, Huang C, Hughes S, Kornfeld K. Valproic acid extends Caenorhabditis elegans lifespan. Aging Cell. 2008;7:305-17.

35. Forthun RB, Sengupta T, Skjeldam HK, Lindvall JM, McCormack E, Gjertsen $B T$, et al. Cross-species functional genomic analysis identifies resistance genes of the histone deacetylase inhibitor valproic acid. PLoS One. 2012;7:e48992.

36. Gerstner T, Bell N, König S. Oral valproic acid for epilepsy-long-term experience in therapy and side effects. Expert Opin Pharmacother. 2008;9:285-92.

37. Duenas-Gonzalez A, Candelaria M, Perez-Plascencia C, Perez-Cardenas E, de la Cruz-Hernandez E, Herrera LA. Valproic acid as epigenetic cancer drug: preclinical, clinical and transcriptional effects on solid tumors. Cancer Treat Rev. 2008;34:206-22.

38. Tan J, McKenzie C, Potamitis M, Thorburn AN, Mackay CR, Macia L. The role of short-chain fatty acids in health and disease. Adv Immunol. 2014;121:91-119.

39. West AC, Johnstone RW. New and emerging HDAC inhibitors for cancer treatment. J Clin Invest. 2014;124:30-9.

40. Xu WS, Parmigiani RB, Marks PA. Histone deacetylase inhibitors: molecular mechanisms of action. Oncogene. 2007;26:5541-52.

41. Halsall J, Gupta V, O'Neill LP, Turner BM, Nightingale KP. Genes are often sheltered from the global histone hyperacetylation induced by HDAC inhibitors. PLoS One. 2012;7:e33453.

42. Rada-Iglesias A, Enroth S, Ameur A, Koch CM, Clelland GK, RespuelaAlonso $\mathrm{P}$, et al. Butyrate mediates decrease of histone acetylation centered on transcription start sites and down-regulation of associated genes. Genome Res. 2007;17:708-19.

43. Peart MJ, Smyth GK, van Laar RK, Bowtell DD, Richon VM, Marks PA, et al. Identification and functional significance of genes regulated by structurally different histone deacetylase inhibitors. Proc Natl Acad Sci USA. 2005;102:3697-702

44. Van Lint C, Emiliani S, Verdin E. The expression of a small fraction of cellular genes is changed in response to histone hyperacetylation. Gene Expr. 1996;5:245-53.

45. Smith CL. A shifting paradigm: histone deacetylases and transcriptional activation. BioEssays. 2008;30:15-24

46. Yang X-J, Seto E. The Rpd3/Hda1 family of lysine deacetylases: from bacteria and yeast to mice and men. Nat Rev Mol Cell Biol. 2008;9:206-18.

47. Kelly RDW, Cowley SM. The physiological roles of histone deacetylase (HDAC) 1 and 2: complex co-stars with multiple leading parts. Biochem Soc Trans. 2013:41:741-9.

48. Jamaladdin S, Kelly RDW, O'Regan L, Dovey OM, Hodson GE, Millard CJ, et al. Histone deacetylase (HDAC) 1 and 2 are essential for accurate cell division and the pluripotency of embryonic stem cells. Proc Natl Acad Sci USA. 2014;111:9840-5.

49. Seto E, Yoshida M. Erasers of histone acetylation: the histone deacetylase enzymes. Cold Spring Harb Perspect Biol. 2014;6:a018713.

50. Lombardi PM, Cole KE, Dowling DP, Christianson DW. Structure, mechanism, and inhibition of histone deacetylases and related metalloenzymes. Curr Opin Struct Biol. 2011;21:735-43.

51. Fu M, Liu M, Sauve AA, Jiao X, Zhang X, Wu X, et al. Hormonal control of androgen receptor function through SIRT1. Mol Cell Biol. 2006;26:8122-35

52. Welsbie DS, Xu J, Chen Y, Borsu L, Scher HI, Rosen N, et al. Histone deacetylases are required for androgen receptor function in hormone-sensitive and castrate-resistant prostate cancer. Cancer Res. 2009;69:958-66.

53. Downey M, Johnson JR, Davey NE, Newton BW, Johnson TL, Galaang $S$, et al. Acetylome profiling reveals overlap in the regulation of diverse processes by sirtuins, gcn5, and esa1. Mol Cell Proteom. 2015;14:162-76.

54. Jack J, Rotroff D, Motsinger-Reif A. Lymphoblastoid cell lines models of drug response: successes and lessons from this pharmacogenomic model. Curr Mol Med. 2014;14:833-40.
55. Huang DW, Sherman BT, Lempicki RA. Systematic and integrative analysis of large gene lists using DAVID bioinformatics resources. Nat Protoc. 2009;4:44-57.

56. Huang Q, Cheung AP, Zhang Y, Huang H-F, Auersperg N, Leung PCK. Effects of growth differentiation factor 9 on cell cycle regulators and ERK42/44 in human granulosa cell proliferation. Am J Physiol Endocrinol Metab. 2009:296:E1344-53.

57. Omtzigt JG, Nau H, Los FJ, Pijpers L, Lindhout D. The disposition of valproate and its metabolites in the late first trimester and early second trimester of pregnancy in maternal serum, urine, and amniotic fluid: effect of dose, co-medication, and the presence of spina bifida. Eur J Clin Pharmacol. 1992;43:381-8.

58. Bantscheff M, Hopf C, Savitski MM, Dittmann A, Grandi P, Michon A-M, et al. Chemoproteomics profiling of HDAC inhibitors reveals selective targeting of HDAC complexes. Nat Biotechnol. 2011;29:255-65.

59. Di Croce L, Helin K. Transcriptional regulation by Polycomb group proteins. Nat Struct Mol Biol. 2013;20:1147-55.

60. Konze KD, Ma A, Li F, Barsyte-Lovejoy D, Parton T, Macnevin CJ, et al. An orally bioavailable chemical probe of the Lysine Methyltransferases EZH2 and EZH1. ACS Chem Biol. 2013;8:1324-34.

61. Xu B, On DM, Ma A, Parton T, Konze KD, Pattenden SG, et al. Selective inhibition of EZH2 and EZH1 enzymatic activity by a small molecule suppresses MLL-rearranged leukemia. Blood. 2015;125:346-57.

62. Leeb M, Pasini D, Novatchkova M, Jaritz M, Helin K, Wutz A. Polycomb complexes act redundantly to repress genomic repeats and genes. Genes Dev. 2010;24:265-76.

63. Saunders N, Dicker A, Popa C, Jones S, Dahler A. Histone deacetylase inhibitors as potential anti-skin cancer agents. Cancer Res. 1999;59:399-404.

64. Yoshida M, Beppu T. Reversible arrest of proliferation of rat $3 Y 1$ fibroblasts in both the $\mathrm{G} 1$ and $\mathrm{G} 2$ phases by trichostatin A. Exp Cell Res. 1988;177:122-31.

65. Kim B, Park H, Salvador LA, Serrano PE, Kwan JC, Zeller SL, et al. Evaluation of class I HDAC isoform selectivity of largazole analogues. Bioorg Med Chem Lett. 2014;24:3728-31.

66. Newkirk TL, Bowers AA, Williams RM. Discovery, biological activity, synthesis and potential therapeutic utility of naturally occurring histone deacetylase inhibitors. Nat Prod Rep. 2009;26:1293-320.

67. Sauer J, Richter KK, Pool-Zobel BL. Physiological concentrations of butyrate favorably modulate genes of oxidative and metabolic stress in primary human colon cells. J Nutr Biochem. 2007;18:736-45.

68. Yadav H, Lee J-H, Lloyd J, Walter P, Rane SG. Beneficial metabolic effects of a probiotic via butyrate-induced GLP-1 hormone secretion. J Biol Chem. 2013:288:25088-97.

69. Yoshida M, Nomura S, Beppu T. Effects of trichostatins on differentiation of murine erythroleukemia cells. Cancer Res. 1987;47:3688-91.

70. Johnke J, Cohen Y, de Leeuw M, Kushmaro A, Jurkevitch E, Chatzinotas A. Multiple micro-predators controlling bacterial communities in the environment. Curr Opin Biotechnol. 2014;27:185-90.

71. Fujioka M, Sun G, Jaynes JB. The Drosophila eve insulator Homie promotes eve expression and protects the adjacent gene from repression by polycomb spreading. PLoS Genet. 2013;9:e1003883.

72. Schwartz YB, Pirrotta V. Ruled by ubiquitylation: a new order for polycomb recruitment. Cell Rep. 2014;8:321-5.

73. Gil J, O'Loghlen A. PRC1 complex diversity: where is it taking us? Trends Cell Biol. 2014;24:632-41.

74. Hansen KH, Bracken AP, Pasini D, Dietrich N, Gehani SS, Monrad A, et al. A model for transmission of the H3K27me3 epigenetic mark. Nat Cell Biol. 2008;10:1291-300.

75. Voigt P, Leroy G, Drury WJ, Zee BM, Son J, Beck DB, et al. Asymmetrically modified nucleosomes. Cell. 2012;151:181-93.

76. Gehani SS, Agrawal-Singh S, Dietrich N, Christophersen NS, Helin K, Hansen K. Polycomb group protein displacement and gene activation through MSK-dependent H3K27me3S28 phosphorylation. Mol Cell. 2010;39:886-900.

77. Lau PNI, Cheung P. Histone code pathway involving H3 S28 phosphorylation and K27 acetylation activates transcription and antagonizes polycomb silencing. Proc Natl Acad Sci USA. 2011;108:2801-6.

78. Sawicka A, Hartl D, Goiser M, Pusch O, Stocsits RR, Tamir IM, et al. H3S28 phosphorylation is a hallmark of the transcriptional response to cellular stress. Genome Res. 2014;24:1808-20. 
79. Bock I, Dhayalan A, Kudithipudi S, Brandt O, Rathert P, Jeltsch A. Detailed specificity analysis of antibodies binding to modified histone tails with peptide arrays. Epigenetics. 2011;6:256-63.

80. Alder O, Lavial F, Helness A, Brookes E, Pinho S, Chandrashekran A, et al. Ring1B and Suv39h1 delineate distinct chromatin states at bivalent genes during early mouse lineage commitment. Development. 2010;137:2483-92.

81. Azuara V, Perry P, Sauer S, Spivakov M, Jørgensen HF, John RM, et al. Chromatin signatures of pluripotent cell lines. Nat Cell Biol. 2006;8:532-8.

82. Stock JK, Giadrossi S, Casanova M, Brookes E, Vidal M, Koseki H, et al. Ring 1-mediated ubiquitination of $\mathrm{H} 2 \mathrm{~A}$ restrains poised RNA polymerase II at bivalent genes in mouse ES cells. Nat Cell Biol. 2007;9:1428-35.

83. Landeira D, Sauer S, Poot R, Dvorkina M, Mazzarella L, Jørgensen HF, et al. Jarid2 is a PRC2 component in embryonic stem cells required for multilineage differentiation and recruitment of PRC1 and RNA polymerase II to developmental regulators. Nat Cell Biol. 2010;12:618-24.
84. Rowe M, Young LS, Crocker J, Stokes H, Henderson S, Rickinson AB. Epstein-Barr virus (EBV)-associated lymphoproliferative disease in the SCID mouse model: implications for the pathogenesis of EBV-positive lymphomas in man. J Exp Med. 1991;173:147-58.

85. White DA, Belyaev ND, Turner BM. Preparation of site-specific antibodies to acetylated histones. Methods. 1999;19:417-24.

86. Saeed Al, Sharov V, White J, Li J, Liang W, Bhagabati N, et al. TM4: a free, open-source system for microarray data management and analysis. Biotechniques. 2003;34:374-8.

87. O'Neill LP, Turner BM. Immunoprecipitation of native chromatin: NChIP. Methods. 2003:31:76-82.

88. Quail MA, Swerdlow H, Turner DJ. Improved protocols for the illumina genome analyzer sequencing system. Curr Protoc Hum Genet. 2009;18:18.2.

89. Langmead B, Salzberg SL. Fast gapped-read alignment with Bowtie 2. Nat Methods. 2012;9:357-9.

\section{Submit your next manuscript to BioMed Central and take full advantage of:}

- Convenient online submission

- Thorough peer review

- No space constraints or color figure charges

- Immediate publication on acceptance

- Inclusion in PubMed, CAS, Scopus and Google Scholar

- Research which is freely available for redistribution

Submit your manuscript at 